\title{
Effect of a fixed-dose combination of Telmisartan/S-amlodipine on circadian blood pressure compared with Telmisartan monotherapy: TENUVA-BP study
}

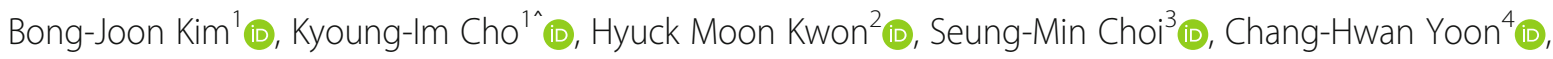
Sang Wook Lim ${ }^{5}$, Seung-Jae Joo ${ }^{6}$ (D) Nam Ho Lee ${ }^{7}$, Sang-Yup Lim ${ }^{8}$, Seong-Hoon Lim ${ }^{9}$ (D) and

Hyo-Soo $\mathrm{Kim}^{10^{*}}$ (D)

\begin{abstract}
Background: This study evaluated the circadian efficacy of a telmisartan $40 \mathrm{mg} / \mathrm{S}$-amlodipine $2.5 \mathrm{mg}$ fixed-dose combination (Telmisartan40/S-Amlodipine2.5) compared to telmisartan $80 \mathrm{mg}$ (Telmisartan80) in patients with essential hypertension who did not respond to 2-4 weeks' treatment with telmisartan $40 \mathrm{mg}$.

Methods: Eligible patients with essential hypertension (clinic mean sitting systolic blood pressure [MSSBP] $\geq 140$ $\mathrm{mmHg}$, or $\geq 130 \mathrm{mmHg}$ in those with diabetes mellitus or chronic kidney disease) were randomly assigned to Telmisartan40/S-Amlodipine2.5 or Telmisartan 80 for 8 weeks. All patients underwent ambulatory BP monitoring (ABPM) at baseline and 8 weeks later. Primary endpoints were changes in mean 24-h SBP and DBP on 24-h ABPM from baseline after 8 weeks. Secondary endpoints were changes in daytime, nighttime, and morning SBP and DBP, and clinic MSSBP and MSDBP.
\end{abstract}

Results: A total of 316 Korean patients were enrolled, 217 patients were randomized to treatment, and 192 patients completed the study. Compared to Telmisartan80, Telmisartan40/S-Amlodipine2.5 showed significantly better reductions in 24-h mean SBP and DBP after 8 weeks. Telmisartan40/S-Amlodipine2.5 also significantly reduced secondary endpoints compared to Telmisartan80. Among 15 adverse events (7 [Telmisartan40/S-Amlodipine2.5] and 8 [Telmisartan80]), there were five adverse drug reactions; 14 events were mild, and none were identified with significant between-group differences.

\footnotetext{
* Correspondence: usahyosoo@gmail.com

After completion of the study and prior to submission of the manuscript,

Kyoung-Im Cho passed away. All authors agreed to retain Kyoung-Im Cho as

an author.

Kyoung-Im Cho is deceased

${ }^{10}$ Department of Internal Medicine, Seoul National University College of

Medicine, Seoul, Republic of Korea

Full list of author information is available at the end of the article
}

C C The Author(s). 2022 Open Access This article is licensed under a Creative Commons Attribution 4.0 International License, which permits use, sharing, adaptation, distribution and reproduction in any medium or format, as long as you give appropriate credit to the original author(s) and the source, provide a link to the Creative Commons licence, and indicate if changes were made. The images or other third party material in this article are included in the article's Creative Commons licence, unless indicated otherwise in a credit line to the material. If material is not included in the article's Creative Commons licence and your intended use is not permitted by statutory regulation or exceeds the permitted use, you will need to obtain permission directly from the copyright holder. To view a copy of this licence, visit http://creativecommons.org/licenses/by/4.0/ The Creative Commons Public Domain Dedication waiver (http://creativecommons.org/publicdomain/zero/1.0/) applies to the data made available in this article, unless otherwise stated in a credit line to the data. 
Conclusions: Telmisartan40/S-Amlodipine2.5 was tolerable and more effective than Telmisartan80 in lowering 24-h mean ambulatory BP in patients with essential hypertension not responding adequately to Telmisartan40. Our findings support the fact that the combination of S-amlodipine with telmisartan is more appropriate than increasing the dose of telmisartan monotherapy.

Trial registration: ClinicalTrials.gov, NCT02231788. Registered 4 September 2014.

Keywords: Amlodipine, Circadian rhythm, Drug combinations, Essential hypertension, Telmisartan

\section{Background}

According to the Korea Hypertension Fact Sheet 2020, with the rapid aging of the population, the absolute number of people with hypertension (HTN) has steadily increased; as of 2018 , the number has exceeded 12 million. Since 1998, the HTN awareness rate has increased and treatment rates have improved; however, the control rate was $47 \%$, a level that still needs further improvement [1]. In terms of recognition of the requirement for more active blood pressure (BP) control, the American Heart Association revised the diagnostic guidelines for HTN, reducing the cut-off to $130 / 80 \mathrm{mmHg}$. More than two-thirds of patients with hypertension require treatment with two or more antihypertensive drugs to achieve their target BP goals [2, 3]. The European Society of Cardiology recommends initial combination therapy for the majority of patients with HTN [4].

In the diagnosis and treatment of HTN, accurate measurement of BP is important in clinical practice, and a single BP measurement at an office is generally not adequate to assess BP fluctuations. According to the Korean ambulatory BP monitoring (ABPM) Registry for Evaluation of the Prognostic Threshold in Hypertension (Kor-ABP), about $30 \%$ of subjects not using ABPM were misdiagnosed in clinical practice regardless of their antihypertensive medication status [5]. Nighttime BP is also a stronger risk factor for coronary heart disease (CHD) and stroke than clinic BP, and a non-dipping pattern has been associated with an increased risk for cardiovascular (CV) events and all-cause mortality [6, 7]. Because ABPM can provide better prognostic information than BP measurements in the clinic, it is emphasized in guidelines, including those from the Korean Society of Hypertension.

It is well known that combination therapies are more effective than monotherapy in meta-analysis [8], and a renin-angiotensin system inhibitor + calcium channel blockers are the most commonly recommended combinations [9-11]. In particular, the combination of telmisartan and amlodipine has considerable clinical evidence supporting its beneficial antihypertensive efficacy for the longest half-life in each class $[12,13]$. S-amlodipine is the more active isomer of amlodipine besylate, which is effective for HTN caused by fluid retention due to its additional natriuretic activity [14]. Telmisartan, which is long-acting and has a plasma half-life of $24 \mathrm{~h}[15,16]$, acts selectively on angiotensin II receptors. Recently, a fixed-dose combination of S-amlodipine besylate $2.5 \mathrm{mg}$ and telmisartan $40 \mathrm{mg}$ has been developed for treating HTN.

There is a lack of studies that compare the effects of single drug and combination therapy on BP reduction, including circadian BP in patients with HTN but not resistant HTN. The aim of this study was to determine the circadian efficacy of combined HTN treatment with telmisartan $40 \mathrm{mg}$ and S-amlodipine besylate $2.5 \mathrm{mg}$ (Telmisartan40/S-Amlodipine2.5) compared with telmisartan $80 \mathrm{mg}$ (Telmisartan80) in patients with HTN who did not respond to telmisartan $40 \mathrm{mg}$ (Telmisartan40) monotherapy.

\section{Methods}

\section{Study design}

This was a multicenter, randomized, parallel-group comparative phase IV clinical trial followed by an 8week open-label extension period (NCT02231788). Patients who agreed to participate in the clinical trial and met the inclusion and exclusion criteria had an initial telmisartan $40 \mathrm{mg}$ treatment period of 2-4 weeks. Patients considered appropriate for this trial were randomly assigned at a 1:1 ratio to the Telmisartan40/S-Amlodipine2.5 group or to the control Telmisartan 80 group. To ensure a balanced allocation of subjects, the randomization sequence generated using SAS version 9.4 (SAS Institute Inc., Cary, NC, USA) was used to construct a random block of 4 , stratified by the participating center and the presence of diabetes mellitus (DM) and chronic kidney disease (CKD). All patients received Telmisartan40/S-Amlodipine 2.5 or Telmisartan 80 once daily during the 8week treatment period (Fig. S1). The study protocol was approved by the Institutional Review Board at each institution. All eligible patients provided written informed consent to participate. 


\section{Study populations}

Patients were enrolled between May 2014 and March 2018. Inclusion criteria included age $\geq 19$ years and clinic mean seated SBP (MSSBP) $\geq 140 \mathrm{mmHg}(\geq 130 \mathrm{mmHg}$ in patients with DM or CKD) despite treatment with telmisartan $40 \mathrm{mg}$ during the initial treatment period. Exclusion criteria were extensive and included a clinic MSSBP $\geq 200 \mathrm{mmHg}$ or a clinic mean seated DBP (MSDBP) $\geq 120 \mathrm{mmHg}$ on screening and randomization; nighttime workers; patients with abnormal liver function (AST/ ALT $>3$ times the upper limit of normal [ULN]) or abnormal renal function (serum creatinine $>4$ times ULN); and patients with secondary HTN (coarctation of aorta, Cushing's syndrome, pheochromocytoma, and primary aldosteronism) except for HTN due to DM and CKD. Those with heart failure (New York Heart Association functional class III-IV); a history of myocardial infarction, unstable angina, significant valvular heart disease, or cardiac arrhythmia requiring treatment within the previous 3 months; a history of severe cerebrovascular disease such as a stroke or cerebral hemorrhage within the previous 6 months; and patients scheduled for renal transplantation during the clinical trial were also excluded. Other exclusion criteria included patients with severe or malignant retinopathy, patients with acute or chronic inflammation requiring treatment, a history of malignancy within 5 years, and a history of angioedema for angiotensin-converting enzyme inhibitor or angiotensin receptor blocker. Patients with known severe hypersensitivity to amlodipine or telmisartan; patients with a condition that may significantly affect the absorption, distribution, and excretion of the clinical trial drugs; patients in need of concomitant use of an HTN drug other than the clinical trial drugs during the period of the clinical trial; and patients who took other clinical trial drugs within the previous 30 days were similarly excluded. A history of alcohol or drug dependency, current pregnancy or lactation, and potential pregnancy without proper contraception also resulted in exclusion.

\section{Blood pressure measurement}

All BP measurements were taken with sponsor-supplied sphygmomanometers (OMRON HEM-7080 IT from Omron Healthcare Co., Ltd. for clinic BP measurements, and Watch BP O3/3MZ1 from Microlife Corp. for ABPM measurements, $\mathrm{NeiHu}$, Taipei). At visit 1, clinic $\mathrm{BP}$ was calculated as the mean of three measurements taken at 2-min intervals on both arms. The arm showing the higher SBP was used as the baseline, and that arm was used at future clinic visits. ABPM was performed on the right arm in the left-handed subjects and on the left arm in the right-handed subjects. All ABPM measurement were proceeded by $24 \mathrm{~h}$ clock-based definition.

\section{Study efficacy endpoints}

The primary endpoints were the changes in the mean 24-h SBP and DBP on 24-h ABPM from the reference baseline after 8 weeks of the treatment period.

The secondary endpoints were:

1) The reduction from the reference baseline in the mean daytime (06:00-21:59) SBP and DBP on 24-h ABPM after 8 weeks of the treatment period.

2) The reduction from the reference baseline in the mean nighttime (22:00-05:59) SBP and DBP on 24-h ABPM after 8 weeks of the treatment period.

3) The reduction from the reference baseline in the mean morning (06:00-11:59) SBP and DBP on 24-h ABPM after 8 weeks of the treatment period.

4) The reduction from the reference baseline in the clinic mean seated SBP and DBP after 8 weeks of the treatment period.

5) The mean ABPM control rate at trough after 8 weeks of the treatment period:

- mean 24-h SBP < 130 mmHg and mean 24-h DBP < $80 \mathrm{mmHg}$

- mean daytime (06:00-21:59) SBP < $135 \mathrm{mmHg}$ and mean daytime DBP $<85 \mathrm{mmHg}$

- mean nighttime (22:00-05:59) SBP < $120 \mathrm{mmHg}$ and mean daytime DBP $<70 \mathrm{mmHg}$

- clinic MSSBP < $140 \mathrm{mmHg}$ and MSDBP < $90 \mathrm{mmHg}$ (clinic MSSBP $<130 \mathrm{mmHg}$ and MSDBP $<80$ $\mathrm{mmHg}$ in patients with $\mathrm{DM}$ or CKD)

6) The mean ABPM response rate at trough after 8 weeks of the treatment period:

- mean 24-h SBP reduction $\geq 10 \mathrm{mmHg}$ and mean 24$h$ DBP reduction $\geq 10 \mathrm{mmHg}$

- clinic MSSBP reduction $\geq 10 \mathrm{mmHg}$ and clinic MSDBP reduction $\geq 10 \mathrm{mmHg}$

\section{Safety endpoint}

Safety evaluation was used to evaluate the incidence of adverse events. These events were determined by laboratory tests and physical examinations.

\section{Statistical analysis}

Statistical analyses were performed with SAS ver. 9.4. Data normality was tested using the KolmogorovSmirnov test. Values are expressed as means \pm SD for numerical variables or as numbers of participants and their percentages for categorical variables. Student's $t$ test was conducted to confirm that the mean change in ABPM from baseline after 8 weeks was superior in the test group compared to the control group. The analysis of categorical data such as control rate and response rate was performed using the chi-squared test or Fisher's 
exact test. A two-tailed $P$-value less than 0.05 was considered statistically significant.

\section{Results}

\section{Study population}

A total of 316 Korean patients were enrolled; of these, 99 patients were excluded (62 patients who did not meet the SBP criteria after treatment with telmisartan $40 \mathrm{mg}$ during the initial treatment period, 27 patients who withdrew consent, and 10 others). Finally, 217 patients were randomized ( $n=111$ to the Telmisartan40/S-Amlodipine2.5 group and $n=106$ to the Telmisartan 80 group), and a total of 192 patients ( $n=98$ for Telmisartan40/S-Amlodipine 2.5 and $n=94$ for Telmisartan80) completed the final study protocol (Fig. 1). The mean age was $63.1 \pm 11.7$ years, and $57.1 \%$ were male. All patients had essential HTN; the mean duration of HTN was $11.6 \pm 9.1$ years. In baseline characteristics, there were no significant differences in age or sex. In addition, both groups showed similar prevalences of DM and CKD and similar durations of HTN (12.0 \pm 9.5 vs. $11.2 \pm$ 8.6 years, $P=0.580$; Table 1 ). Of 184 subjects in the full analysis set, $89.1 \%$ had taken more than one drug before participating in the trial; there was no between-group difference $(88.5 \%$ in Telmisartan40/S-Amlodipine2.5 vs $89.8 \%$ in Telmisartan $80, P=0.789$ ). The mean compliance of the 184 subjects was $97.3 \% \pm 5.3 \%$, with no significant between-group difference (Telmisartan40/SAmlodipine2.5 vs Telmisartan $80, \quad 97.5 \% \pm 4.1 \%$ vs. $97.0 \% \pm 6.3 \%, P=0.505)$.

\section{Primary endpoint}

Subjects in the Telmisartan40/S-Amlodipine2.5 group showed a significantly greater reduction of 24-h mean SBP $(-10.3 \pm 11.5$ vs. $-3.0 \pm 14.1 \mathrm{mmHg}, P<0.001)$ and DBP $(-6.2 \pm 5.7$ vs. $-1.8 \pm 8.0 \mathrm{mmHg}, P<0.001)$ than those in the Telmisartan 80 group after 8 weeks compared to baseline values (Table 2, Fig. 2). Compared to baseline, the mean DBP reduction was statistically significant in both groups $(P<0.001, P=0.038)$, but the mean SBP reduction was significant only in the Telmisartan40/S-Amlodipine2.5 group $(P<0.001)$.

\section{Secondary endpoints}

The Telmisartan40/S-Amlodipine2.5 group showed significantly greater reductions in mean nighttime SBP ($10.1 \pm 14.7$ vs. $-2.8 \pm 17.1 \mathrm{mmHg}, P=0.003)$ and $\mathrm{DBP}$ $(-5.2 \pm 7.8$ vs. $-1.4 \pm 11.3 \mathrm{mmHg}, P=0.010$ ) (Table 2). The Telmisartan40/S-Amlodipine2.5 group also showed significantly lower reductions of mean daytime (06:0021:59) SBP $(-10.5 \pm 11.9$ vs. $-2.6 \pm 14.2 \mathrm{mmHg}, P<$ $0.001)$ and DBP $(-6.6 \pm 6.0$ vs. $-1.6 \pm 8.0 \mathrm{mmHg}, P<$ $0.001)$, mean morning (06:00-11:59) SBP $(-8.4 \pm 12.8$ vs. $-3.1 \pm 14.2 \mathrm{mmHg}, P=0.009)$ and DBP $(-6.0 \pm 7.7$ vs. $-1.8 \pm 8.7 \mathrm{mmHg}, P<0.001)$ and clinic MSSBP ($15.4 \pm 15.3$ vs. $\quad-5.9 \pm 14.1 \mathrm{mmHg}, \quad P<0.001) \quad$ and $\operatorname{MSDBP} \quad(-7.7 \pm 9.1$ vs. $\quad-1.6 \pm 8.9 \mathrm{mmHg}, \quad P<0.001)$ compared to the Telmisartan 80 group after 8 weeks compared to baseline values.

Table 3 shows the control rates and response rates of patients after 8 weeks. The percentages of patients who achieved 24-h-mean SBP/DBP $<130 / 80 \mathrm{mmHg}$ in

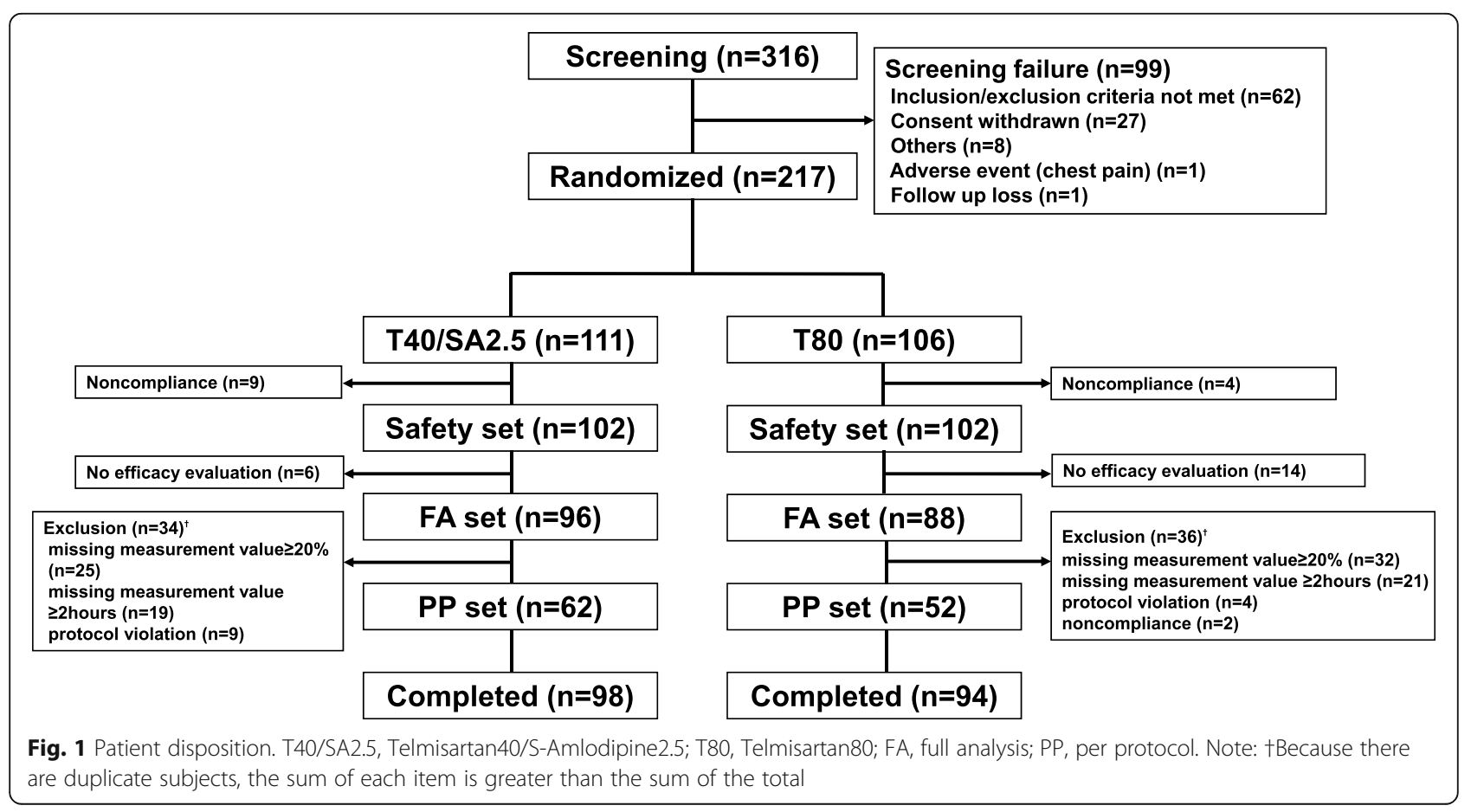


Table 1 Baseline characteristics

\begin{tabular}{|c|c|c|c|c|}
\hline & $\begin{array}{l}\text { All Subjects } \\
(n=184)\end{array}$ & $\begin{array}{l}\text { Telmisartan40/S-Amlodipine2.5 } \\
(n=96)\end{array}$ & $\begin{array}{l}\text { Telmisartan80 } \\
(n=88)\end{array}$ & $P$-value \\
\hline Male $(n, \%)$ & $105(57.1)$ & $59(61.5)$ & $46(52.3)$ & $0.209^{\mathrm{a})}$ \\
\hline Age, mean (year) & $63.1 \pm 11.7$ & $63.5 \pm 12.5$ & $62.7 \pm 10.9$ & $0.650^{\mathrm{b})}$ \\
\hline Height $(\mathrm{cm})$ & $162.3 \pm 8.6$ & $163.0 \pm 8.2$ & $161.6 \pm 9.0$ & $0.270^{\mathrm{a})}$ \\
\hline Body weight (kg) & $70.0 \pm 13.8$ & $69.6 \pm 11.1$ & $70.5 \pm 16.3$ & $0.650^{\mathrm{a})}$ \\
\hline HTN (n, \%) & $184(100.0)$ & $96(100.0)$ & $88(100.0)$ & \\
\hline Duration of HTN, mean (year) & $11.6 \pm 9.1$ & $12.0 \pm 9.5$ & $11.2 \pm 8.6$ & $0.580^{\mathrm{a})}$ \\
\hline $\mathrm{DM}(\mathrm{n}, \%)$ & $65(35.3)$ & $33(34.4)$ & $32(36.4)$ & $0.778^{a)}$ \\
\hline Duration of DM (year) & $8.0 \pm 9.2$ & $7.3 \pm 7.4$ & $8.8 \pm 10.8$ & $0.532^{b)}$ \\
\hline CKD $(n, \%)$ & $34(18.5)$ & $18(18.8)$ & $16(18.2)$ & $0.921^{\text {a) }}$ \\
\hline Office SBP (mmHg) & $153.1 \pm 15.5$ & $154.8 \pm 16.0$ & $151.2 \pm 14.9$ & $0.111^{a)}$ \\
\hline Office DBP (mmHg) & $89.2 \pm 11.9$ & $88.9 \pm 12.5$ & $89.6 \pm 11.4$ & $0.677^{\mathrm{a})}$ \\
\hline Heart rate (bpm) & $73.2 \pm 12.6$ & $72.6 \pm 13.3$ & $73.9 \pm 11.7$ & $0.486^{\mathrm{a})}$ \\
\hline Body temperature $\left({ }^{\circ} \mathrm{C}\right)$ & $36.5 \pm 0.2$ & $36.5 \pm 0.2$ & $36.5 \pm 0.2$ & $0.920^{\mathrm{a})}$ \\
\hline
\end{tabular}

${ }^{a)}$ Result of chi-square test. ${ }^{\text {b) }}$ Result of Fisher's exact for comparison between the two groups

HTN, hypertension; DM, diabetes mellitus; CKD, chronic kidney disease; SBP, systolic blood pressure DBP, diastolic blood pressure

8 weeks were $70.8 \%$ with Telmisartan40/S-Amlodipine 2.5 and $45.5 \%$ with Telmisartan 80 . The percentages of patients who achieved daytime mean SBP/ DBP $<135 / 85 \mathrm{mmHg}$ and nighttime mean SBP/DBP $<130 / 80 \mathrm{mmHg}$ in 8 weeks were 77.1 and $50.0 \%$, respectively, with Telmisartan40/S-Amlodipine 2.5 and 59.1 and $34.1 \%$, respectively, with Telmisartan 80 . The control rate of office BP $(<140 / 90 \mathrm{mmHg})$ was $19.8 \%$ with Telmisartan40/S-Amlodipine2.5 and 9.1\% with Telmisartan 80 . All values were significantly better with Telmisartan40/S-Amlodipine2.5 compared to Telmisartan 80 .

The percentages of patients who achieved 24-h-mean SBP/DBP reduction $\geq 10 / 10 \mathrm{mmHg}$ after 8 weeks compared to baseline were $20.8 \%$ (20 of 96) in the Telmisartan40/S-Amlodipine2.5 group and 9.1\% (8 of 88) in the Telmisartan 80 group; there was a significant difference between the two groups $(P=0.027)$. The percentages of patients who achieved clinic MSSBP/MSDBP reduction $\geq 10 / 10 \mathrm{mmHg}$ after 8 weeks compared to baseline were $30.2 \%$ ( 29 of 96) in the Telmisartan40/SAmlodipine2.5 group and 15.9\% (14 of 88) in the Telmisartan 80 group; there was a significant betweengroup difference $(P=0.022)$.

When we analyzed the changes in BP variability in the 24-h ABPM data of our patients (Table S1), Telmisartan40/S-Amlodipine2.5 showed a tendency to reduce the standard deviation (SD) of 24-h SBP/DBP more, but there was no statistical significance (change of SD of 24 -h SBP $-0.55 \pm 4.26$ vs. $-0.04 \pm 3.87, P=$ 0.406 , change of SD of 24-h DBP $-0.35 \pm 2.94$ vs. $0.14 \pm 3.37, P=0.296)$.

\section{Safety}

Table 4 shows adverse events during the study period according to treatment group. Among the 204 subjects in the safety set, 13 patients (6.4\%) experienced 15 cases of adverse events, and there was no difference between the two groups $(6.9 \%$ in the Telmisartan $40 / \mathrm{S}$-Amlodipine2.5 group vs. $5.9 \%$ in the Telmisartan 80 group, $P=$ 0.774). Most (14 of 15) of the adverse events were mild; there were no serious adverse events. Adverse drug reactions (ADRs) were identified in 3 of the Telmisartan40/ S-Amlodipine2.5 group patients (2.9\%) and 2 of the Telmisartan 80 group patients $(2.0 \%)$; there was no betweengroup difference $(P=1.000)$. The three ADRs in the Telmisartan40/S-Amlodipine2.5 group were peripheral edema, increased LDL, and hypotension (1 case each). The two ADRs in the Telmisartan80 group were otitis media chronic (1 case) and generalized pruritus (1 case). All ADRs were also mild events; all were assessed as 'recovering/resolving' and 'recovered/resolved'.

\section{Discussion}

Current Korean guidelines (The 2018 Korean Association of Hypertension Guidelines) suggest that if there is no adequate response to single drug therapy at stage 1 HTN with low to moderate risk, as an option in the next treatment plan, it may be possible to change to another class of drug, to increase the single drug dose, or to use combination therapy. Of course, it is difficult to apply the same guidelines because the biological and environmental characteristics of Westerners and Asians are different, but this is considered less aggressive than guidelines from Europe or the United States for 
Table 2 Changes in 24-h ABPM: efficacy outcomes

\begin{tabular}{|c|c|c|c|}
\hline & $\begin{array}{l}\text { Telmisartan40/S-Amlodipine2.5 } \\
(n=96)\end{array}$ & $\begin{array}{l}\text { Telmisartan80 } \\
(n=88)\end{array}$ & $P$-value ${ }^{\text {a) }}$ \\
\hline \multicolumn{4}{|c|}{$24 \mathrm{~h}$ mean SBP $(\mathrm{mmHg})$} \\
\hline Baseline & $132.6 \pm 14.0$ & $130.3 \pm 13.8$ & \\
\hline Week 8 & $122.5 \pm 11.8$ & $127.4 \pm 15.6$ & \\
\hline Change & $-10.3 \pm 11.5$ & $-3.0 \pm 14.1$ & $<0.001$ \\
\hline \multicolumn{4}{|c|}{$24 \mathrm{~h}$ mean DBP $(\mathrm{mmHg})$} \\
\hline Baseline & $78.0 \pm 10.6$ & $78.5 \pm 11.0$ & \\
\hline Week 8 & $71.8 \pm 8.1$ & $76.8 \pm 11.8$ & \\
\hline Change & $-6.2 \pm 5.7$ & $-1.8 \pm 8.0$ & $<0.001$ \\
\hline \multicolumn{4}{|c|}{ Nighttime mean SBP (mmHg) } \\
\hline Baseline & $128.5 \pm 15.9$ & $123.1 \pm 14.7$ & \\
\hline Week 8 & $115.4 \pm 11.2$ & $120.7 \pm 18.0$ & \\
\hline Change & $-10.1 \pm 14.7$ & $-2.8 \pm 17.1$ & 0.003 \\
\hline \multicolumn{4}{|c|}{ Nighttime mean DBP (mmHg) } \\
\hline Baseline & $72.7 \pm 10.8$ & $73.3 \pm 11.0$ & \\
\hline Week 8 & $67.4 \pm 8.1$ & $72.0 \pm 13.2$ & \\
\hline Change & $-5.2 \pm 7.8$ & $-1.4 \pm 11.3$ & 0.010 \\
\hline \multicolumn{4}{|c|}{ Mean daytime (06:00 21:59) SBP (mmHg) } \\
\hline Baseline & $135.3 \pm 14.7$ & $132.8 \pm 14.4$ & \\
\hline Week 8 & $125.1 \pm 13.1$ & $130.2 \pm 15.6$ & \\
\hline Change & $-10.5 \pm 11.9$ & $-2.6 \pm 14.2$ & $<0.001$ \\
\hline \multicolumn{4}{|c|}{ Mean daytime DBP (06:00 21:59) (mmHg) } \\
\hline Baseline & $79.9 \pm 11.1$ & $80.3 \pm 11.7$ & \\
\hline Week 8 & $73.4 \pm 8.8$ & $78.8 \pm 11.9$ & \\
\hline Change & $-6.6 \pm 6.0$ & $-1.6 \pm 8.0$ & $<0.001$ \\
\hline \multicolumn{4}{|c|}{ Mean morning-time $(06: 00 \sim 11: 59)$ SBP $(\mathrm{mmHg})$} \\
\hline Baseline & $134.7 \pm 13.6$ & $133.6 \pm 14.4$ & \\
\hline Week 8 & $126.7 \pm 14.1$ & $130.7 \pm 15.1$ & \\
\hline Change & $-8.4 \pm 12.8$ & $-3.1 \pm 14.2$ & 0.009 \\
\hline \multicolumn{4}{|c|}{ Mean morning-time (06:00 11:59) DBP (mmHg) } \\
\hline Baseline & $80.6 \pm 9.9$ & $81.0 \pm 11.1$ & \\
\hline Week 8 & $74.7 \pm 9.4$ & $79.2 \pm 11.5$ & \\
\hline Change & $-6.0 \pm 7.7$ & $-1.8 \pm 8.7$ & $<0.001$ \\
\hline \multicolumn{4}{|c|}{ Mean office SBP (mmHg) } \\
\hline Baseline & $154.8 \pm 16.0$ & $151.2 \pm 14.9$ & \\
\hline Week 8 & $139.4 \pm 16.7$ & $145.3 \pm 16.0$ & \\
\hline Change & $-15.4 \pm 15.3$ & $-5.9 \pm 14.1$ & $<0.001$ \\
\hline \multicolumn{4}{|c|}{ Mean office DBP (mmHg) } \\
\hline Baseline & $88.9 \pm 12.5$ & $89.6 \pm 11.4$ & \\
\hline Week 8 & $81.2 \pm 11.13$ & $88.0 \pm 1.8$ & \\
\hline Change & $-7.7 \pm 9.1$ & $-1.6 \pm 8.9$ & $<0.001$ \\
\hline
\end{tabular}

$A B P M$ ambulatory blood pressure monitoring, $S B P$ systolic blood pressure, $D B P$ diastolic blood pressure

${ }^{a}$ Result of independent $t$-test for comparison between two groups 


\section{4h mean SBP}

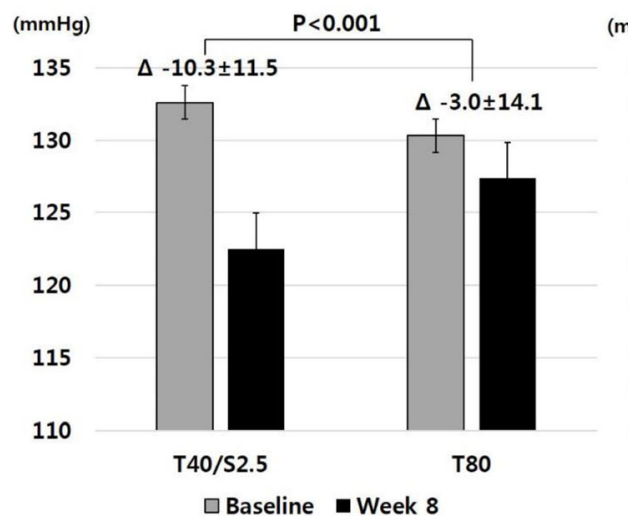

24h mean DBP

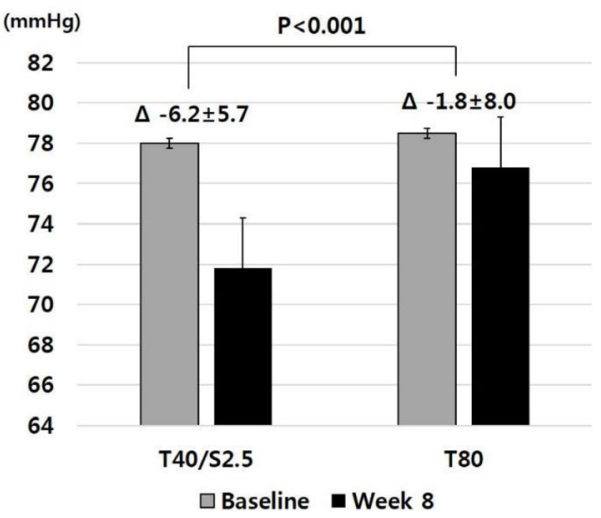

Fig. 2 Comparison of changes in 24-h mean SBP/DBP according to treatment groups. SBP, systolic blood pressure; DBP, diastolic blood pressure; T40, Telmisartan40; SA2.5, S-Amlodipine2.5; T80, Telmisartan80

combination treatment. In our study, the enrolled patients were relatively older, had a long duration of HTN, and did not respond to relatively low doses of HTN medication. In these patient groups, Telmisartan40/SAmlodipine2.5 reduced 24-h mean SBP and DBP to a significantly greater extent than Telmisartan 80 . So, our results showed that even in Asian patients with 'not severe' HTN, the combination is more effective in lowering the BP, it supports the recent trend in which initial combination is emphasized. Several clinical trials have shown a greater antihypertensive effect with the amlodipine and telmisartan combination. Previous studies showed that the telmisartan/amlodipine combination was superior to amlodipine monotherapy in reducing BP (TEAMSTA-5 study) [13], and S-amlodipine/telmisartan exhibited superior antihypertensive effects compared with S-amlodipine monotherapy in the Korean population [17]. Compared to these studies, the significant feature of our study was that the diagnosis and therapeutic effects on circadian BP were all evaluated by 24-h ABPM. Clinic BP can be affected significantly by temperature, physical activity, emotional stress, caffeine, and alcohol. In particular, the white coat effect is a major cause of HTN misdiagnosis [18]. Therefore, due to the large number of measurements, ABPM provides a reliable estimate of an individual's $\mathrm{BP}$ and can be used as an important tool to measure BP and to accurately determine the effects of HTN therapy [19], and it also provides information on BP during daytime activity and sleep, making $\mathrm{ABPM}$ a better predictor of target organ damage than clinic BP [20].

Another important finding of our study was that Telmisartan40/S-Amlodipine2.5 also significantly lowered nighttime, daytime, and morning BPs as well as 24h mean BP compared to Telmisartan80. Nighttime HTN and morning HTN also have an important meaning and they are associated with a higher risk of total mortality and all CV events [21, 22]. Especially in the Asian population, nighttime HTN is more common due to high salt intake and sensitivity [23]. Although it is difficult to clearly explain this mechanism, it is possible that the synergistic effect of the telmisartan/amlodipine

Table 3 Blood pressure control rate and response rate after 8 weeks

\begin{tabular}{|c|c|c|c|}
\hline & $\begin{array}{l}\text { Telmisartan40/S-Amlodipine2.5 } \\
(n=96)\end{array}$ & $\begin{array}{l}\text { Telmisartan80 } \\
(n=88)\end{array}$ & $P$-value \\
\hline \multicolumn{4}{|l|}{ BP control rate, $\mathrm{n}(\%)$} \\
\hline Mean $24 \mathrm{~h}(00: 00 \sim 23: 59)$ SBP/DBP $<130 / 80 \mathrm{mmHg}$ & $68(70.8)$ & $40(45.5)$ & $<0.001^{\mathrm{a})}$ \\
\hline Mean Daytime $(06: 00 \sim 21: 59)$ SBP/DBP $<135 / 85$ mmHg & $74(77.1)$ & $52(59.1)$ & $0.009^{a)}$ \\
\hline Mean Nighttime (22:00 05:59) SBP/DBP < 130/80 mmHg & $48(50.0)$ & $30(34.1)$ & $0.025^{\mathrm{a})}$ \\
\hline Clinic MSSBP/MSDBP < 140/90 mmHg & $19(19.8)$ & $8(9.1)$ & $0.040^{\mathrm{a})}$ \\
\hline \multicolumn{4}{|l|}{ BP response rate, $\mathrm{n}(\%)$} \\
\hline Mean $24 \mathrm{~h}(00: 00 \sim 23: 59)$ SBP/DBP reduction $\geq 10 / 10 \mathrm{mmHg}$ & $20(20.8)$ & $8(9.1)$ & $0.027^{\mathrm{a})}$ \\
\hline Clinic MSSBP/MSDBP reduction $\geq 10 / 10 \mathrm{mmHg}$ & $29(30.2)$ & $14(15.9)$ & $0.022^{\mathrm{a})}$ \\
\hline
\end{tabular}

$B P$ blood pressure, SBP systolic blood pressure, DBP diastolic blood pressure, MS mean sitting

${ }^{\text {a) }}$ Result of chi-square test 
Table 4 Summary of adverse events during the study period according to treatment groups (Safety set)

\begin{tabular}{|c|c|c|c|c|}
\hline & $\begin{array}{l}\text { All Subjects } \\
(n=204)\end{array}$ & $\begin{array}{l}\text { Telmisartan40/S-Amlodipine2.5 } \\
(n=102)\end{array}$ & $\begin{array}{l}\text { Telmisartan80 } \\
(n=102)\end{array}$ & $P$-value \\
\hline Overall AE, n (\%) [no. of cases] & $13(6.37)[15]$ & $7(6.86)[7]$ & $6(5.88)[8]$ & $0.774^{\mathrm{a})}$ \\
\hline ADR & $5(2.45)[5]$ & $3(2.94)[3]$ & $2(1.96)[2]$ & $1.000^{b)}$ \\
\hline SAE & - & - & - & \\
\hline Infections and infestations & $3(1.47)[3]$ & $1(0.98)[1]$ & $2(1.96)[2]$ & $1.000^{\mathrm{b})}$ \\
\hline Herpes zoster & $1(0.49)[1]$ & $1(0.98 \%)[1]$ & - & $1.000^{\mathrm{b})}$ \\
\hline Nasopharyngitis & $1(0.49)[1]$ & - & $1(0.98)[1]$ & $1.000^{\mathrm{b})}$ \\
\hline Otitis media chronic & $1(0.49)[1]$ & - & $1(0.98)[1]$ & $1.000^{\mathrm{b})}$ \\
\hline Skin and subcutaneous tissue disorders & $3(1.47)[3]$ & $2(1.96)[2]$ & $1(0.98)[1]$ & $1.000^{b)}$ \\
\hline Photosensitivity reaction & $1(0.49)[1]$ & $1(0.98)[1]$ & - & $1.000^{\mathrm{b})}$ \\
\hline Pruritus generalised & $1(0.49)[1]$ & - & $1(0.98)[1]$ & $1.000^{\mathrm{b})}$ \\
\hline Urticaria & $1(0.49)[1]$ & $1(0.98)[1]$ & - & $1.000^{\mathrm{b})}$ \\
\hline Investigations & $2(0.98)[2]$ & $1(0.98)[1]$ & $1(0.98)[1]$ & $1.000^{\mathrm{b})}$ \\
\hline Blood glucose increased & $1(0.49)[1]$ & - & $1(0.98)[1]$ & $1.000^{b)}$ \\
\hline Low density lipoprotein increased & $1(0.49)[1]$ & $1(0.98)[1]$ & - & $1.000^{\mathrm{b})}$ \\
\hline Nervous system disorders & $2(0.98)[2]$ & - & $2(1.96)[2]$ & $0.498^{b)}$ \\
\hline Headache & $1(0.49)[1]$ & - & $1(0.98)[1]$ & $1.000^{\mathrm{b})}$ \\
\hline Migraine without aura & $1(0.49)[1]$ & - & $1(0.98)[1]$ & $1.000^{\mathrm{b})}$ \\
\hline Cardiac disorders & $1(0.49)[1]$ & - & $1(0.98)[1]$ & $1.000^{\mathrm{b})}$ \\
\hline Palpitations & $1(0.49)[1]$ & - & $1(0.98)[1]$ & $1.000^{b)}$ \\
\hline Eye disorders & $1(0.49)[1]$ & - & $1(0.98)[1]$ & $1.000^{\mathrm{b})}$ \\
\hline Dry eye & $1(0.49)[1]$ & - & $1(0.98)[1]$ & $1.000^{b)}$ \\
\hline General disorders and administration site conditions & $1(0.49)[1]$ & $1(0.98)[1]$ & - & $1.000^{\mathrm{b})}$ \\
\hline Oedema peripheral & $1(0.49)[1]$ & $1(0.98)[1]$ & - & $1.000^{b)}$ \\
\hline Psychiatric disorders & $1(0.49)[1]$ & $1(0.98)[1]$ & - & $1.000^{\mathrm{b})}$ \\
\hline Insomnia & $1(0.49)[1]$ & $1(0.98)[1]$ & - & $1.000^{\mathrm{b})}$ \\
\hline Vascular disorders & $1(0.49)[1]$ & $1(0.98)[1]$ & - & $1.000^{\mathrm{b})}$ \\
\hline Hypotension & $1(0.49)[1]$ & $1(0.98)[1]$ & - & $1.000^{\mathrm{b})}$ \\
\hline
\end{tabular}

${ }^{a)}$ Result of chi-square test. ${ }^{\text {b) }}$ Result of Fisher's exact for comparison between two groups

$A E$ adverse event, $A D R$ adverse drug reaction, $S A E$ serious adverse event

combination was more effective in correcting arteriolar vasodilatation and arterial stiffness [24-26]. This pathophysiology can be understood as the concept of BP variability. Although BP variability is not synonymous with $\mathrm{BP}$ reduction, in terms of effective $\mathrm{BP}$ control, BP variability is also clinically important and it is associated with CV events [27]. A previous study showed that the telmisartan/amlodipine combination was associated with a smoother BP reduction over $24 \mathrm{~h}$ and with a more favorable balance between mean 24-h BP reduction and the degree of BP variability on treatment, reflecting both its effectiveness in lowering BP levels and its longer duration of action [28]. Although our results have not statistically proven that Telmisartan40/S-Amlodipine2.5 lowers BP variability more than Telmisartan 80 , perhaps this is due to the insufficient number of enrolled patients. Therefore, even considering the long-acting characteristics of telmisartan, our result may support that Telmisartan40/S-Amlodipine2.5 is more effective to control BP constantly and stably than Telmisartan 80 .

During the study period, a total of 15 adverse events were identified, and most of them (14 of $15 ; 1$ was considered moderate) were mild. There were also no severe ADRs. Our safety findings align with those from other studies using telmisartan [29]. The incidence of adverse events suggests that the Telmisartan40/S-Amlodipine2.5 combination is relatively tolerable. Peripheral edema was noted in one patient in the Telmisartan40/S-Amlodipine2.5 group (1.0\%), a finding that is usually associated with amlodipine; the incidence of edema with conventional amlodipine therapy is $\geq 10 \%$ [30]. A previous study showed that with S-amlodipine, the incidence of peripheral edema was lower [30], whereas another study also showed that S-amlodipine was associated with less ankle 
edema than amlodipine besylate in Korean women with mild to moderate HTN [31]. This may be due to the Samlodipine dosage being equivalent to half the dosage of amlodipine besylate. In addition, S-amlodipine is effective against HTN caused by fluid retention (renin-independent) by acting on sodium diuretics as well as influencing vasodilation [14, 32]. Conventional amlodipine also releases nitric oxide through stimulation of inducible nitric oxide synthase in a concentrationdependent manner, whereas S-amlodipine does not. This may be a reason for the lower incidence of peripheral edema [33]. Our findings support the fact that Telmisar$\tan 40 / \mathrm{S}$-Amlodipine2.5 is tolerable compared to Telmisartan80 in terms of peripheral edema.

Our study has several limitations. First, this is an unblinded trial. Second, the number of enrolled patients was small, and the study duration was short. Therefore, our study is limited to short-term BP reduction effects, and there are limitations in evaluating long-term BP lowering effects or CV outcomes. Third, our study did not strictly control for lifestyle modification. Fourth, the study population was all Korean, making generalizations to other ethnic groups difficult. However, our study has the strength of measuring BP by ABPM at diagnosis and follow-up, allowing us to minimize errors of BP measurement and evaluate circadian BP variation.

\section{Conclusions}

Compared to Telmisartan80, the Telmisartan40/S-Amlodipine2.5 combination was more effective in lowering circadian BP in patients with essential HTN who did not respond adequately to Telmisartan40. There was no difference in safety. Our findings support the hypothesis that combining S-amlodipine with telmisartan is more appropriate than increasing the dose of telmisartan monotherapy.

\section{Abbreviations \\ ABPM: Ambulatory blood pressure monitoring; ADR: Adverse drug reaction; BP: Blood pressure; CKD: Chronic kidney disease; CV: Cardiovascular; CVD: Cardiovascular disease; DBP: Diastolic blood pressure; DM: Diabetes mellitus; HTN: Hypertension; MS: Mean sitting; MSDBP: Mean sitting diastolic blood pressure; MSSBP: Mean sitting systolic blood pressure; SBP: Systolic blood pressure; SD: Standard deviation; ULN: Upper limit of normal}

\section{Supplementary Information}

The online version contains supplementary material available at https://doi. org/10.1186/s40885-021-00184-0.

\section{Additional file 1: Study design}

Additional file 2: Changes in BP variabilityafter treatment

\section{Acknowledgments}

Under the guidance of the authors, professional medical writing/editorial support was provided by David P. Figgitt, PhD, ISMPP CMPPTM, Content Ed Net, with funding from Chong Kun Dang Pharmaceutical Co., Ltd.

\section{Authors' contributions}

All authors were study investigators, made substantial contributions to the acquisition, analysis and interpretation of data, were involved in the preparation of the manuscript, and provided critical revision for intellectual content. All authors read and approved the final manuscript.

\section{Funding}

This study was initiated and supported financially by Chong Kun Dang Pharmaceutical Co., Ltd. The company provided financial support for the medicines and laboratory tests and for engaging the clinical research coordinator. The funding body had no role in the analysis and interpretation of the data or in the writing of the manuscript.

\section{Availability of data and materials}

The datasets used and/or analysed during the current study are available from the corresponding author on reasonable request.

\section{Declarations}

Ethics approval and consent to participate

The study protocol was approved by the Institutional Review Board at each institution.

\section{Consent for publication}

Not applicable.

\section{Competing interests}

All authors declare that they have no conflicts of interest regarding the content of this article.

\section{Author details}

${ }^{1}$ Division of Cardiology, Department of Internal Medicine, Kosin University College of Medicine, Gospel Hospital, Busan, Republic of Korea. ${ }^{2}$ Cardiology Division, Department of Internal Medicine, Gangnam Severance Hospital, Yonsei University, Seoul, Republic of Korea. ${ }^{3}$ Department of Cardiology, National Medical Center, Seoul, Republic of Korea. ${ }^{4}$ Division of Cardiology, Department of Internal Medicine, Seoul National University Bundang Hospital, Seongnam, Republic of Korea. ${ }^{5}$ Division of Cardiology, Department of Internal Medicine, CHA Bundang Medical Center, CHA University, Seongnam, Republic of Korea. ${ }^{6}$ Department of Internal Medicine, Jeju National University Hospital, Jeju, Republic of Korea. 'Department of Internal Medicine, Hallym University Kangnam Sacred Heart Hospital, Seoul, Republic of Korea. ${ }^{8}$ Department of Cardiology, Korea University Ansan Hospital, Ansan, Republic of Korea. ${ }^{9}$ Cardiovascular Division, Department of Internal Medicine, Dankook University Hospital, Cheonan, Republic of Korea. ${ }^{10}$ Department of Internal Medicine, Seoul National University College of Medicine, Seoul, Republic of Korea.

Received: 11 May 2021 Accepted: 7 November 2021

Published online: 01 March 2022

References

1. Kim HC, Cho SM, Lee H, Lee HH, Baek J, Heo JE, et al. Korea hypertension fact sheet 2020: analysis of nationwide population-based data. Clin Hypertens. 2021;27(1):8. https://doi.org/10.1186/s40885-021-00166-2.

2. Weber MA, Schiffrin EL, White WB, Mann S, Lindholm LH, Kenerson JG, et al. Clinical practice guidelines for the management of hypertension in the community: a statement by the American Society of Hypertension and the International Society of Hypertension. J Clin Hypertens (Greenwich). 2014;16: 14-26.

3. Shin J, Park JB, Kim KI, Kim JH, Yang DH, Pyun WB. 2013 Korean Society of Hypertension guidelines for the management of hypertension: part IItreatments of hypertension. Clin Hypertens. 2015;21 (1):2. https://doi.org/1 0.1186/s40885-014-0013-2.

4. Williams B, Mancia G, Spiering W, Agabiti Rosei E, Azizi M, Burnier M, et al. 2018 practice guidelines for the management of arterial hypertension of the European Society of Cardiology and the European Society of Hypertension. Blood Press. 2018;27(6):314-40. https://doi.org/10.1080/0803 7051.2018 .1527177$.

5. Shin J, Park SH, Kim JH, Ihm SH, Kim KI, Kim WS, et al. Discordance between ambulatory versus clinic blood pressure according to global cardiovascular 
risk group. Korean J Intern Med. 2015;30(5):610-9. https://doi.org/10.3904/ kjim.2015.30.5.610.

6. Asayama K, Fujiwara T, Hoshide S, Ohkubo T, Kario K, Stergiou GS. Nocturnal blood pressure measured by home devices: evidence and perspective for clinical application. J Hypertens. 2019;37(5):905-16. https://doi.org/10.1097/ HJH.0000000000001987.

7. Head GA. The importance and prognostic value of nocturnal blood pressure assessments using inexpensive domestic devices. J Hypertens. 2017;35(3): 463-5. https://doi.org/10.1097/HJH.0000000000001244.

8. Wald DS, Law M, Morris JK, Bestwick JP, Wald NJ. Combination therapy versus monotherapy in reducing blood pressure: meta-analysis on 11,000 participants from 42 trials. Am J Med. 2009;122(3):290-300. https://doi.org/1 0.1016/j.amjmed.2008.09.038.

9. Kjeldsen SE, Narkiewicz K, Burnier M, Oparil S. 2018 practice guidelines for the management of arterial hypertension of the European Society of Hypertension. Blood Press. 2018;27(6):313. https://doi.org/10.1080/0803 7051.2018.1530564.

10. Liu L, Zhang Y, Liu G, Li W, Zhang X, Zanchetti A, et al. The Felodipine event reduction (FEVER) study: a randomized long-term placebo-controlled trial in Chinese hypertensive patients. J Hypertens. 2005;23(12):2157-72. https://doi.org/10.1097/01.hjh.0000194120.42722.ac

11. Davis BR. Whelton PK; ALLHAT collaborative research group. Benazepril plus amlodipine or hydrochlorothiazide for hypertension. N Engl J Med. 2009; 360(11):1148-9.

12. Littlejohn TW 3rd, Majul CR, Olvera R, Seeber M, Kobe M, Guthrie R, et al. Results of treatment with telmisartan-amlodipine in hypertensive patients. J Clin Hypertens (Greenwich). 2009;11:207-13.

13. Neldam S, Lang M, Jones R. TEAMSTA-5 Investigators. Telmisartan and amlodipine single-pill combinations vs amlodipine monotherapy for superior blood pressure lowering and improved tolerability in patients with uncontrolled hypertension: results of the TEAMSTA-5 study. J Clin Hypertens (Greenwich). 2011;13:459-66.

14. Kim SA, Park S, Chung N, Lim DS, Yang JY, Oh BH, et al. Efficacy and safety profiles of a new $\mathrm{S}(-)$-amlodipine nicotinate formulation versus racemic amlodipine besylate in adult Korean patients with mild to moderate hypertension: an 8-week, multicenter, randomized, double-blind, doubledummy, parallel-group, phase III, noninferiority clinical trial. Clin Ther. 2008; 30(5):845-57. https://doi.org/10.1016/j.clinthera.2008.05.013.

15. Kakuta H, Sudoh K, Sasamata M, Yamagishi S. Telmisartan has the strongest binding affinity to angiotensin II type 1 receptor: comparison with other angiotensin II type 1 receptor blockers. Int J Clin Pharmacol Res. 2005;25(1): 41-6.

16. Lacourcière Y, Krzesinski JM, White WB, Davidai G, Schumacher H. Sustained antihypertensive activity of telmisartan compared with valsartan. Blood Press Monit. 2004;9(4):203-10. https://doi.org/10.1097/00126097-20040800000005.

17. Ihm SH, Jeon HK, Cha TJ, Hong TJ, Kim SH, Lee NH, et al. Efficacy and safety of two fixed-dose combinations of S-amlodipine and telmisartan (CKD-828) versus S-amlodipine monotherapy in patients with hypertension inadequately controlled using S-amlodipine monotherapy: an 8-week, multicenter, randomized, double-blind, phase III clinical study. Drug Des Devel Ther. 2016;10:3817-26. https://doi.org/10.2147/DDDT.S116847.

18. Nordmann A, Frach B, Walker T, Martina B, Battegay E. Reliability of patients measuring blood pressure at home: prospective observational study. BMJ. 1999;319(7218):1172. https://doi.org/10.1136/bmj.319.7218.1172.

19. Pickering TG, Shimbo D, Haas D. Ambulatory blood-pressure monitoring. N Engl J Med. 2006;354(22):2368-74. https://doi.org/10.1056/NEJMra060433.

20. Staessen JA, Thijs L, Fagard R, O'Brien ET, Clement D, de Leeuw PW, et al. Predicting cardiovascular risk using conventional vs ambulatory blood pressure in older patients with systolic hypertension. Systolic hypertension in Europe trial investigators. JAMA. 1999;282(6):539-46. https://doi.org/10.1 001/jama.282.6.539.

21. Fan HQ, Li Y, Thijs L, Hansen TW, Boggia J, Kikuya M. Prognostic value of isolated nocturnal hypertension on ambulatory measurement in 8711 individuals from 10 populations. J Hypertens. 2010;28(10):2036-45. https:// doi.org/10.1097/HJH.0b013e32833b49fe.

22. Kario K, Pickering TG, Umeda Y, Hoshide S, Hoshide Y, Morinari M, et al. Morning surge in blood pressure as a predictor of silent and clinical cerebrovascular disease in elderly hypertensives: a prospective study. Circulation. 2003;107(10):1401-6. https://doi.org/10.1161/01.CIR.0000056521. 67546.AA.
23. Li Y, Staessen JA, Lu L, Li LH, Wang GL, Wang JG. Is isolated nocturnal hypertension a novel clinical entity? Findings from a Chinese population study. Hypertension. 2007;50(2):333-9. https://doi.org/10.1161/ HYPERTENSIONAHA.107.087767.

24. White WB, Littlejohn TW, Majul CR, Oigman W, Olvera R, Seeber M, et al. Effects of telmisartan and amlodipine in combination on ambulatory blood pressure in stages 1-2 hypertension. Blood Press Monit. 2010;15(4):205-12. https://doi.org/10.1097/MBP.0b013e32833c5722.

25. Lund-Johansen P, Omvik P, White W, Digranes O, Helland B, Jordal O, et al. Long-term haemodynamic effects of amlodipine at rest and during exercise in essential hypertension. Postgrad Med J. 1991;67(Suppl 5):S20-3.

26. O'Rourke MF, Mancia G. Arterial stiffness. J Hypertens. 1999;17(1):1-4. https:// doi.org/10.1097/00004872-199917010-00001.

27. Sander D, Kukla C, Klingelhöfer J, Winbeck K, Conrad B. Relationship between circadian blood pressure patterns and progression of early carotid atherosclerosis: a 3-year follow-up study. Circulation. 2000;102(13):1536-41. https://doi.org/10.1161/01.CIR.102.13.1536.

28. Parati G, Dolan E, Ley L, Schumacher H. Impact of antihypertensive combination and monotreatments on blood pressure variability: assessment by old and new indices. Data from a large ambulatory blood pressure monitoring database. J Hypertens. 2014;32(6):1326-33. https://doi.org/10.1 097/HJH.0000000000000169.

29. Higaki J, Komuro I, Shiki K, Ugai H, Taniguchi A, Ikeda H, et al. The efficacy and long-term safety of a triple combination of $80 \mathrm{mg}$ telmisartan, $5 \mathrm{mg}$ amlodipine and $12.5 \mathrm{mg}$ hydrochlorothiazide in Japanese patients with essential hypertension: a randomized, double-blind study with open-label extension. Hypertens Res. 2017;40(1):51-60. https://doi.org/10.1038/hr.2016.1 00.

30. Beckey C, Lundy A, Lutfi N. Lercanidipine in the treatment of hypertension. Ann Pharmacother. 2007:41(3):465-73. https://doi.org/10.1345/aph.1H299.

31. Oh GC, Lee HY, Kang HJ, Zo JH, Choi DJ, Oh BH. Quantification of pedal edema during treatment with $\mathrm{S}(-)$-amlodipine nicotinate versus amlodipine besylate in female Korean patients with mild to moderate hypertension: a 12-week, multicenter, randomized, double-blind, active-controlled, phase IV clinical trial. Clin Ther. 2012;34(9):1940-7. https://doi.org/10.1016/j.clinthera.2 012.08.003.

32. National Kidney Foundation. K/DOQI clinical practice guidelines for chronic kidney disease: evaluation, classification, and stratification. Am J Kidney Dis. 2002;39:51-266.

33. Zhang XP, Loke KE, Mital S, Chahwala S, Hintze TH. Paradoxical release of nitric oxide by an L-type calcium channel antagonist, the R+ enantiomer of amlodipine. J Cardiovasc Pharmacol. 2002;39(2):208-14. https://doi.org/10.1 097/00005344-200202000-00007.

\section{Publisher's Note}

Springer Nature remains neutral with regard to jurisdictional claims in published maps and institutional affiliations.

Ready to submit your research? Choose BMC and benefit from:

- fast, convenient online submission

- thorough peer review by experienced researchers in your field

- rapid publication on acceptance

- support for research data, including large and complex data types

- gold Open Access which fosters wider collaboration and increased citations

- maximum visibility for your research: over $100 \mathrm{M}$ website views per year

At BMC, research is always in progress.

Learn more biomedcentral.com/submissions 